\title{
A Semiactive Skyhook-Inertance Control Strategy Based on Continuously Adjustable Inerter
}

\author{
Xiao-Liang Zhang $\mathbb{D}$, Tian Zhang, Jiamei Nie, and Long Chen $(1)$ \\ School of Automotive and Traffic Engineering, Jiangsu University, Zhenjiang, Jiangsu, China \\ Correspondence should be addressed to Xiao-Liang Zhang; zxl1979@ujs.edu.cn
}

Received 30 September 2017; Revised 31 December 2017; Accepted 4 February 2018; Published 1 March 2018

Academic Editor: Evgeny Petrov

Copyright ( 2018 Xiao-Liang Zhang et al. This is an open access article distributed under the Creative Commons Attribution License, which permits unrestricted use, distribution, and reproduction in any medium, provided the original work is properly cited.

\begin{abstract}
This paper presents a modified skyhook-inertance control strategy which is realized through a hydraulic device of continuously adjustable inertance between sprung mass and unsprung mass. The parasitic damping inherent in the hydraulic device as well as the inertance is taken into account in the modified control strategy. Differential equation models are built to compare the performance of the semiactive suspension employing the modified control strategy with that of the passive suspension. The results demonstrate that the semiactive suspension significantly reduces sprung mass natural frequency, attenuates the resonant peak value without the penalty of deterioration at higher frequencies, and achieves over $28 \%$ improvement on ride comfort, compared with the passive suspension in unload condition. The proposed hydraulic device, together with its control strategy, can be used to reduce the variation of sprung mass natural frequency and ride comfort between unload and full-load condition.
\end{abstract}

\section{Introduction}

Vehicle suspension is designed to isolate the passengers from road disturbances, to limit rigid body motion of the vehicle, and to force contact between the wheels and the road, respectively, called ride comfort, suspension travel, and road holding [1]. Although multiobjective optimization is a trend in suspension design, the most important and basic issue to be studied is the ride comfort [2]. It has been theoretically proved that vehicle suspensions can obtain the improvement of ride comfort with low sprung mass natural frequency [3]. Ride comfort of vehicles, especially for that of trucks, which have passive suspensions with stable design parameters such as spring stiffness and damping coefficient, is mostly influenced by loading conditions [4]. Compared with unloaded vehicle, full-load vehicle has lower sprung mass natural frequency and more desirable performance on ride comfort owing to the larger sprung mass.

Different from passive suspension, semiactive suspension can achieve more desirable performance by employing variable stiffness and damping. Variable stiffness can be realized through air spring or hydropneumatic spring. These elastic components of suspensions are subjected to the static load of vehicle bodies and hence difficultly controlled. The control for dampers is relatively easy and widely used in semiactive suspensions. A number of semiactive strategies, such as skyhook, ground-hook, and hybrid, are proposed, and they can be realized through semiactive dampers [5-9]. These semiactive damping control strategies can effectively minimize the vertical motion of the sprung or unsprung mass, but it can hardly reduce the variation of sprung mass natural frequency and ride comfort between unload and full-load condition. This is due to the fact that both the passive and semiactive suspensions mentioned above are based on the suspension struts of spring-damper rather than inerter-spring-damper.

In 2002, a new ideal mechanical element named the inerter was introduced by Smith [10]. The inerter has two independently movable terminals and has the property that the applied force at the terminals is directly proportional to the relative acceleration between them. As a new mechanical element, the inerter becomes a hot topic and focus in recent years [11-16]. The main motivation of proposing inerter is due to network synthesis, and its realization has drawn many scholars' attention. In the passive network synthesis, a special class of admittances with one damper and one inerter and three-port spring networks with inerter for mechanical 
control have been realized $[17,18]$, and the realization of biquadratic impedance as five-element bridge networks has been addressed and extended to the general five-element bridge networks in the latest research [19]. Since the birth of the inerter, a number of applications of the inerter-springdamper struts in vehicle suspensions have been proposed and investigated. The performance benefits of using the inerterspring-damper struts in vehicle suspension systems have been well demonstrated [20-25]. Particularly, the general conclusion that the inerter can reduce the natural frequencies of the vibration systems provides a way to improve the performances of passive suspensions employing the inerterspring-damper struts [13].

In 2014, the concept of semiactive inerter and inertance control which is totally different from stiffness control and damping control is proposed by Chen et al. [26]. In that work, the proposed LQG control does not aim at reducing the variation of sprung mass natural frequency and ride comfort between unload and full-load condition. In 2017, Hu et al. [27] provided the physical embodiments of semiactive inerter and proved that the semiactive inerter could be realized with a controllable-inertia flywheel. The semiactive inerter, together with its FT and PD controllers, is designed for tuned vibration absorbers instead of vehicle suspensions. In the latest research, the skyhook inerter configuration was used to virtually increase the sprung mass of a vehicle, to improve the ride comfort performance [28]. This research is focused on numerical simulations about the effectiveness and performances of the control laws, without specific inerter devices corresponding to the continuous control law involved.

In this paper, a scheme for hydraulic device of continuously adjustable inertance is proposed. The novelty of this work is that not only the inertance but also the parasitic damping of the device is taken into account in the skyhookinertance control strategy. This modified strategy is proper for the hydraulic inerter device to approximate the virtual skyhook inerter. It is proposed for light commercial vehicle to control the hydraulic device, to reduce the variation of sprung mass natural frequency and ride comfort between unload and full-load condition.

For a virtual skyhook inerter system, its dynamic equations in unload condition are in consistent with those of the passive suspension system in full-load condition, in the case that the inertance of the skyhook inerter is equal to the mass of full cargo or passengers. That implies the virtual skyhook inerter system in unload condition and the passive suspension system in full-load condition have the same performance in theory. Therefore, the skyhook inerter has the potentiality of reducing sprung mass natural frequency and improving ride comfort of passive suspensions in unload condition. Since the skyhook inerter is a theoretical assumption that cannot be passively implemented in actual vehicles, the continuously adjustable inerter device is proposed to address this issue by approximating the virtual skyhook inerter. Furthermore, in this paper, the governing differential equations of the semiactive inertance control suspension are derived and the differential equation model is built by MATLAB/Simulink. The frequency and time responses prove the superiority of the semiactive control suspension in

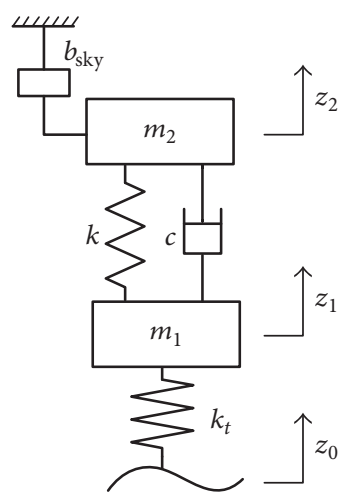

FIgURE 1: A virtual Skyhook inerter system.

reducing sprung mass natural frequency and improving ride comfort in unload condition.

\section{Virtual Skyhook Inerter System}

A virtual skyhook inerter system is aimed at adding virtual mass to the sprung mass and reducing natural frequency of the sprung mass. The virtual inerter is inserted between the sprung mass and the stationary sky (the imaginary reference frame) not only as a way of applying the inertial force to the sprung mass, but also as a tool of computing the desired inertial force.

Figure 1 presents the virtual skyhook inerter system arrangement. Consider a quarter vehicle model made up of a sprung mass $\left(m_{2}\right)$ and an unsprung mass $\left(m_{1}\right)$. A virtual inerter with the inertance $b_{\text {sky }}$ is placed between the inertial reference frame, rather than the moving surface, and the sprung mass. Therefore, the inertial force is proportional to the absolute acceleration of the sprung mass. A spring with the stiffness coefficient $k$ and a damper with the damping coefficient $c$ are settled between the unsprung mass and sprung mass. The tire is modeled by a spring with the stiffness coefficient $k_{t}$. In this model, $z_{2}$ (resp., $z_{1}$ ) is the vertical displacement of $m_{2}$ (resp., $m_{1}$ ) and $z_{0}$ is the road profile.

The inertial force applied to the sprung mass, which is generated by the virtual skyhook inerter, can be expressed as

$$
F_{s}=-b_{\text {sky }} \ddot{z}_{2},
$$

where $b_{\text {sky }}$ is the inertance in $\mathrm{kg}$.

\section{Continuously Adjustable Inerter Device}

A continuously adjustable inerter device, a combination of a hydraulic cylinder and a displacement-dependent inertance valve, is proposed to apply to the semiactive inertance control suspension, which is illustrated in Figure 2.

As is shown in the lower half of Figure 2, the displacement-dependent inertance valve is an internal-helix fluid inertance valve and consists of a moving valve element having a helical channel surrounding its outer surface inside a valve cylinder filled with a fluid. The valve cylinder has an enlarged radius of the internal surface in the right half part, so that the length of the helical path can be variable during the motion of the valve element. 


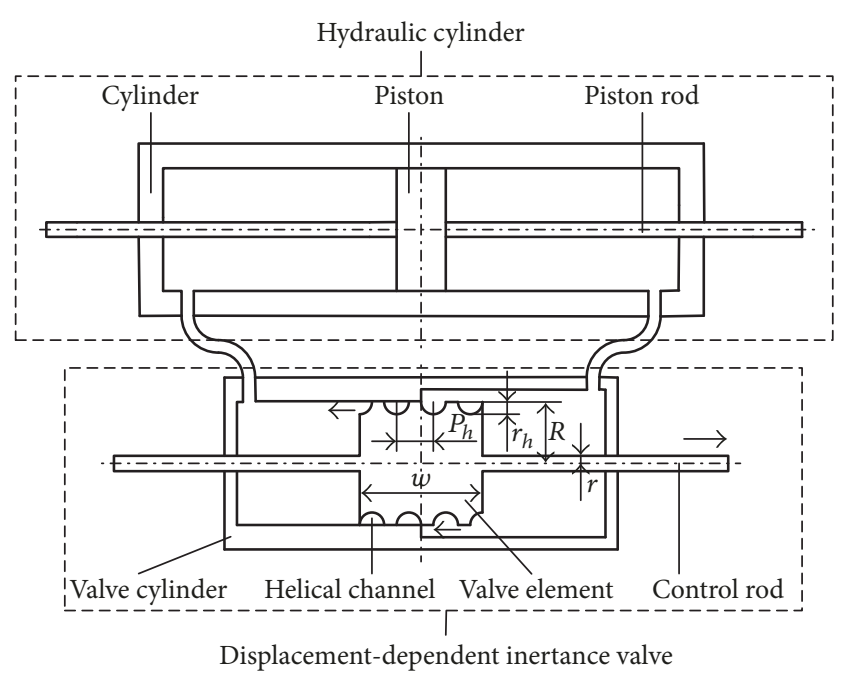

FIgURE 2: A continuously adjustable inerter device.

In the upper half of Figure 2, a hydraulic cylinder consists of a moving piston inside a cylinder filled with the fluid, and the moving piston has a piston rod which is connected to the unsprung mass of the vehicle with the semiactive inertance control suspension. The cylinder is connected to the sprung mass.

Movement of the piston causes the fluid to flow through the helical path which generates an inertial force due to the moving mass of the fluid in the helical path. During the motion of the valve element, the length of the helical path is changed, and the mass of the fluid in the helical path is successively varied. Consequently, the inertance is varied. Since the relative displacement between the control rod and the valve cylinder is continuously controllable, the inertance of the proposed inerter can be continuously adjustable.

Let $A_{1}$ be the effective cross-sectional area of the valve element, namely, the working area of the valve element. Let $R$ be the radius of the valve element, $r$ be the radius of the control rod, $r_{h}$ be the radius of the helical channel, $P_{h}$ be the pitch of the helix, and $w$ be the valve element width. Let $A_{2}$ be the channel cross-sectional area and $\rho$ be the fluid density. Let $x$ be the relative displacement between the valve element and the valve cylinder, $l$ be the channel length, and $l(x)$ be the length of the helical path. Let $S_{1}$ be the effective crosssectional area of the piston, $R_{\mathrm{c}}$ be the radius of the piston, and $r_{\mathrm{c}}$ be the radius of the piston rod.

According to the calculation method of the inertance of the fluid inerter [29], the inertance of the continuously adjustable inerter can be expressed as

$$
B(x)=\rho l(x) \frac{A_{1}^{2}}{A_{2}}\left(\frac{S_{1}}{A_{1}}\right)^{2},
$$

where $S_{1}=\pi\left(R_{\mathrm{c}}^{2}-r_{\mathrm{c}}^{2}\right), A_{1}=\pi\left(R^{2}-r^{2}\right)$, and $A_{2}=(1 / 2) \pi r_{h}^{2}$.

The channel length $l$ can be represented as

$$
l=\frac{w \sqrt{P_{h}^{2}+(2 \pi R)^{2}}}{P_{h}} .
$$

The working width of the valve element, which is linearly related to the length of the helical path, is equal to $w / 2-x$,
TABLE 1: Structural parameters for the continuously adjustable inerter device.

\begin{tabular}{lc}
\hline Description & Value \\
\hline Valve element radius $R$ & $0.05 \mathrm{~m}$ \\
Control rod radius $r$ & $0.006 \mathrm{~m}$ \\
Helix radius $r_{h}$ & $0.007 \mathrm{~m}$ \\
Helix pitch $P_{h}$ & $0.02 \mathrm{~m}$ \\
Valve element width $w$ & $0.12 \mathrm{~m}$ \\
Piston radius $R_{c}$ & $0.05 \mathrm{~m}$ \\
Piston rod radius $r_{c}$ & $0.006 \mathrm{~m}$ \\
Working stroke $r_{L}$ & $0.12 \mathrm{~m}$ \\
\hline
\end{tabular}

where the origin of coordinates is located on the center of the valve cylinder. Obviously, the valve element must run between $-w / 2$ and $w / 2$; that is, $x \in[-w / 2, w / 2]$. Therefore, the length of the helical path $l(x)$ is expressed as

$$
l(x)=\frac{(w / 2-x) \sqrt{P_{h}^{2}+(2 \pi R)^{2}}}{P_{h}} .
$$

It is needed to substitute (4) into (2) as follows:

$$
B(x)=\frac{(w-2 x) \pi \rho\left(R_{\mathrm{c}}^{2}-r_{\mathrm{c}}^{2}\right)^{2} \sqrt{P_{h}^{2}+(2 \pi R)^{2}}}{P_{h} r_{h}^{2}} .
$$

Due to the viscosity of fluid, the parasitic damping inherent in the hydraulic inerter device should be taken into account. It is assumed that the state of fluid in helical channel is laminar flow, which means the value of Reynolds number (Re) is less than $2 \times 10^{3}$. According to the Hagen-Poiseuille flow equation, it is easy to have

$$
u=\frac{r_{h}^{2} \Delta p}{8 \mu l(x)}
$$

where $\Delta p$ is the pressure loss of the fluid flowing through the helical path and $\mu$ is the viscosity of fluid. Hence, the coefficient of parasitic damping of the hydraulic inerter device can be presented as

$$
c_{p}(x)=\frac{\Delta p S_{1}}{\dot{z}}=\frac{\Delta p S_{1}^{2}}{A_{2} u}=8 \pi \mu l(x)\left(\frac{S_{1}}{A_{2}}\right)^{2} .
$$

Equation (7) can be also rewritten as

$$
c_{p}(x)=\frac{16(w-2 x) \pi \mu\left(R_{c}^{2}-r_{c}^{2}\right)^{2} \sqrt{P_{h}^{2}+(2 \pi R)^{2}}}{P_{h} r_{h}^{4}} .
$$

It is shown in (5) and (8) that $B(x)$ and $c_{p}(x)$ are relevant to $x$ and are related as follows:

$$
\alpha=\frac{c_{p}(x)}{B(x)}=\frac{16 \mu}{\rho r_{h}^{2}} .
$$

Equation (9) represents that damping-inertance ratio is relevant to fluid viscosity $\mu$, density $\rho$, and radius of helical channel $r_{h}$.

The values of all structural parameters of the continuously adjustable inerter device are given in Table 1. Silicone oil KF$96 \mathrm{~L}-0.65 \mathrm{cs}$ is chosen as the fluid medium, and its density $\rho$ and viscosity $\mu$ are $960 \mathrm{~kg} \mathrm{~m}^{3}$ and $6.3 \times 10^{-4} \mathrm{~Pa} \mathrm{~s}$, respectively. Thus, the damping-inertance ratio $\alpha$ is calculated as 0.21 . 


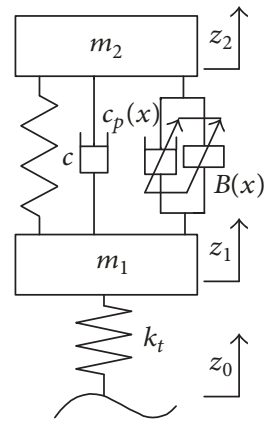

FIgURE 3: A semiactive inertance control suspension.

\section{Semiactive Inertance Control Suspension}

For the virtual skyhook inerter system, since it is impossible to arrange an inerter between the inertial reference frame and the sprung mass in a moving vehicle, the continuously adjustable inerter is used to approximate the virtual inerter. In other words, the continuously adjustable inerter is installed in place of the virtual skyhook inerter shown in Figure 1, and in this way, the virtual skyhook inerter system can be realized by the semiactive inertance control suspension shown in Figure 3.

The resultant force applied to the sprung mass generated by the continuously adjustable inerter includes the inertial force and the parasitic damping force, and it can be represented as

$$
F=-B(x)\left(\ddot{z}_{2}-\ddot{z}_{1}\right)-c_{p}(x)\left(\dot{z}_{2}-\dot{z}_{1}\right)
$$

Substituting (9) into (10) leads to

$$
F=-B(x)\left(\ddot{z}_{2}-\ddot{z}_{1}\right)-\alpha B(x)\left(\dot{z}_{2}-\dot{z}_{1}\right) .
$$

In the case that the continuously adjustable inerter device is used to approximate the skyhook inerter, $F$ is equal to $F_{\mathrm{s}}$ (see (1)); that is,

$$
-b_{\text {sky }} \ddot{z}_{2}=-B(x)\left(\ddot{z}_{2}-\ddot{z}_{1}\right)-\alpha B(x)\left(\dot{z}_{2}-\dot{z}_{1}\right) .
$$

Therefore, the semiactive inertance control law can be expressed as

$$
B(x)=\frac{b_{\text {sky }} \ddot{z}_{2}}{\left(\ddot{z}_{2}-\ddot{z}_{1}\right)+\alpha\left(\dot{z_{2}}-\dot{z_{1}}\right)} .
$$

In practice, the inertance of the continuously adjustable inerter device is limited by the physical parameters, and it means that there are both an upper bound $b_{\max }$ and a lower bound $b_{\min }$ for the inertance. In the case of the constraints $b_{\text {min }} \leq B \leq b_{\text {max }}$, the semiactive inertance control law can be represented in the form

$$
B(x)= \begin{cases}b_{\min } & \text { if } \ddot{z}_{2}\left(\ddot{z}_{2}-\ddot{z}_{1}\right) \leq 0, \frac{b_{\text {sky }} \ddot{z}_{2}}{\left(\ddot{z}_{2}-\ddot{z}_{1}\right)+\alpha\left(\dot{z}_{2}-\dot{z}_{1}\right)} \leq 0 ; \\ \frac{b_{\text {sky }} \ddot{z}_{2}}{\left(\ddot{z}_{2}-\ddot{z}_{1}\right)+\alpha\left(\dot{z}_{2}-\dot{z}_{1}\right)}, & \text { if } \ddot{z}_{2}\left(\ddot{z}_{2}-\ddot{z}_{1}\right)>0,0<\frac{b_{\text {sky }} \ddot{z}_{2}}{\left(\ddot{z}_{2}-\ddot{z}_{1}\right)+\alpha\left(\dot{z}_{2}-\dot{z}_{1}\right)}<b_{\max } \\ b_{\max }, & \text { if } \ddot{z}_{2}\left(\ddot{z}_{2}-\ddot{z}_{1}\right)>0, \frac{b_{\text {sky }}}{\left(\ddot{z}_{2}-\ddot{z}_{1}\right)+\alpha\left(\dot{z}_{2}-\dot{z}_{1}\right)} \geq b_{\max } .\end{cases}
$$

The desired inertance $B(x)$ is obtained according to acceleration of the sprung mass, relative acceleration and relative velocity between the sprung and unsprung mass, and damping-inertance ratio.

\section{A Quarter Vehicle Model Equipped with the Continuously Adjustable Inerter}

Figure 4(a) shows a quarter vehicle model of the unload passive suspension, and its dynamical equations can be written as (15). Figure 4(b) shows a quarter vehicle model of the full-load passive suspension with the passenger or cargo load $m_{c}$, and its dynamical equations can be written as (16). The dynamical equations of the virtual skyhook inerter system in Figures 1 and 4(c) are given by (17). In the case of $m_{\mathrm{c}}=b_{\text {sky }},(16)$ is in consistent with (17), and hence, the virtual skyhook inerter system can be viewed as the equivalent of the passive suspension in full-load condition. The semiactive inertance control suspension in Figure 4(d) is the semiactive equivalent of the virtual skyhook inerter system, and its dynamical equations can be written as (18). The parameters used in the simulation are provided in Table 2.

$$
\begin{aligned}
& m_{2} \ddot{z}_{2}+c\left(\dot{z}_{2}-\dot{z}_{1}\right)+k\left(z_{2}-z_{1}\right)=0, \\
& m_{1} \ddot{z}_{1}-c\left(\dot{z}_{2}-\dot{z}_{1}\right)-k\left(z_{2}-z_{1}\right)+k_{t}\left(z_{1}-z_{0}\right)=0 ; \\
& \left(m_{2}+m_{c}\right) \ddot{z}_{2}+c\left(\dot{z}_{2}-\dot{z}_{1}\right)+k\left(z_{2}-z_{1}\right)=0, \\
& m_{1} \ddot{z}_{1}-c\left(\dot{z}_{2}-\dot{z}_{1}\right)-k\left(z_{2}-z_{1}\right)+k_{t}\left(z_{1}-z_{0}\right)=0 ; \\
& \left(m_{2}+b_{\text {sky }}\right) \ddot{z}_{2}+c\left(\dot{z}_{2}-\dot{z}_{1}\right)+k\left(z_{2}-z_{1}\right)=0, \\
& m_{1} \ddot{z}_{1}-c\left(\dot{z}_{2}-\dot{z}_{1}\right)-k\left(z_{2}-z_{1}\right)+k_{t}\left(z_{1}-z_{0}\right)=0 ; \\
& m_{2} \ddot{z}_{2}+c\left(\dot{z}_{2}-\dot{z}_{1}\right)+k\left(z_{2}-z_{1}\right)+B(x)\left(\ddot{z}_{2}-\ddot{z}_{1}\right)=0, \\
& m_{1} \ddot{z}_{1}-c\left(\dot{z}_{2}-\dot{z}_{1}\right)-k\left(z_{2}-z_{1}\right)-B(x)\left(\ddot{z}_{2}-\ddot{z}_{1}\right) \\
& \quad+k_{t}\left(z_{1}-z_{0}\right)=0 .
\end{aligned}
$$




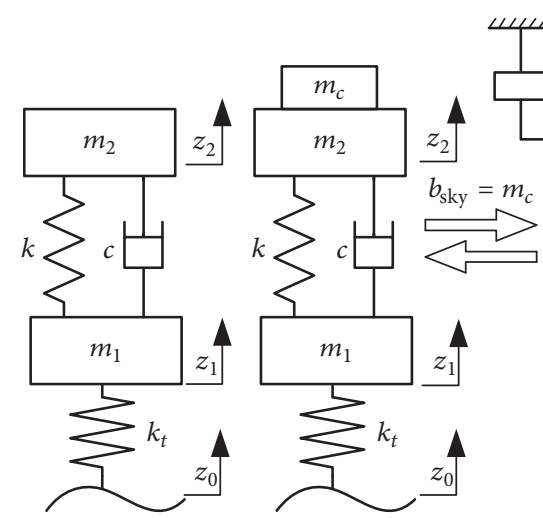

(a) (b)

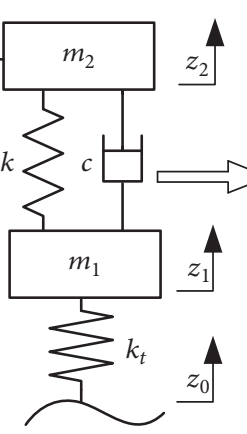

(c)

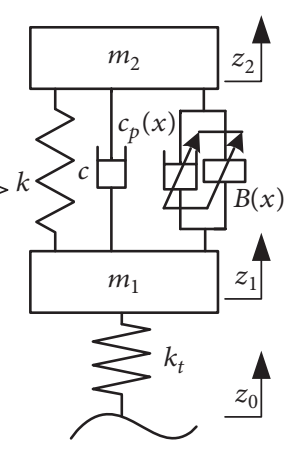

(d)

FIGURE 4: Equivalent relationship between quarter vehicle models: (a) unload passive suspension; (b) full-load passive suspension; (c) virtual skyhook inerter system; (d) semiactive inertance control suspension.

TABle 2: Parameters of the quarter vehicle model.

\begin{tabular}{lc}
\hline Description & Value \\
\hline Unsprung mass $m_{1}$ & $122.5 \mathrm{~kg}$ \\
Sprung mass $m_{2}$ & $500 \mathrm{~kg}$ \\
Passenger or cargo mass $m_{c}$ & $1000 \mathrm{~kg}$ \\
Virtual inertance $b_{\text {sky }}$ & $1000 \mathrm{~kg}$ \\
Suspension stiffness coefficient $k$ & $77.9 \mathrm{kN} \mathrm{m}^{-1}$ \\
Suspension damping coefficient $c$ & $3 \mathrm{kN} \mathrm{s} \mathrm{m}^{-1}$ \\
Tire stiffness coefficient $k_{t}$ & $584 \mathrm{kN} \mathrm{m}^{-1}$ \\
\hline
\end{tabular}

\section{Results and Discussion}

6.1. Frequency Responses to Sinusoidal Excitations. In this paper, to simulate the working condition of a light commercial vehicle, the passenger or cargo mass $m_{c}$ is chosen to be $1000 \mathrm{~kg}$, which means the sprung mass in unload condition $m_{2}$ is $500 \mathrm{~kg}$ while that in full-load condition $m_{2}+m_{c}$ is $1500 \mathrm{~kg}$. To ensure that the natural frequencies are similar in the two different conditions, the semiactive inertance control is applied to simulate the full-load condition when the vehicle is actually in unload condition, in which the sprung mass $m_{2}$ is $500 \mathrm{~kg}$ while the inertance of skyhook inerter $b_{\text {sky }}$ is $1000 \mathrm{~kg}$.

As a numerical example of frequency response, the road velocity input is given as $\dot{z}_{0}=A \sin (2 \pi f t)$, where $f$ varies from $0.1 \mathrm{~Hz}$ to $100 \mathrm{~Hz}$. Here choose $A=0.1 \mathrm{~m} \mathrm{~s}^{-1}$ as amplitude of the road velocity input. The simulation results are presented in Figures 5-7 and Table 3.

Figure 5 shows the root mean square (RMS) values of body acceleration (BA) of the three suspensions (Figures 4(a), $4(\mathrm{~b})$, and $4(\mathrm{~d}))$ in various frequencies. As can be seen in Figure 5 and Table 3, the sprung mass natural frequencies of the passive suspension in unload and in full-load condition are $1.99 \mathrm{~Hz}$ and $1.19 \mathrm{~Hz}$, respectively, and the corresponding peak values at the sprung mass natural frequencies are $3.95 \mathrm{~m}$ $\mathrm{s}^{-2}$ and $2.695 \mathrm{~m} \mathrm{~s}^{-2}$, respectively. Obviously, the passive suspension in full-load condition has lower natural frequency and more desirable ride comfort compared with the one

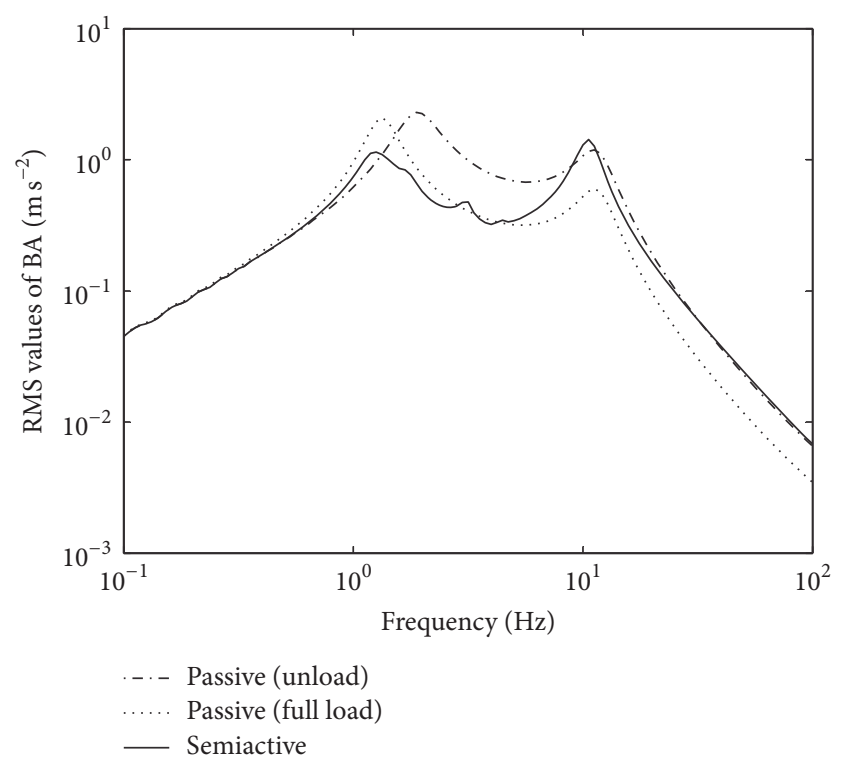

FIGURE 5: Frequency responses of body acceleration.

in unload condition. For the semiactive inertance control suspension with $b_{\text {sky }}=1000 \mathrm{~kg}$, the sprung mass natural frequency is equal to $1.26 \mathrm{~Hz}$. Moreover, the semiactive inertance control suspension has $71.1 \%$ decrease of low frequency peak values, $6.9 \%$ decrease of high frequency peak values compared with the unload passive suspension. It can be concluded that the semiactive inertance control suspension can significantly suppress the peak value of BA at the sprung mass natural frequency, and there are slight improvements at the unsprung mass natural frequency.

Figure 6 shows the RMS values of the suspension working space (SWS) of the three suspensions in various frequencies. It is easily seen that, in the range of $1-3 \mathrm{~Hz}$, the RMS values of SWS are less in the unload passive suspension and more in the full-load passive suspension and semiactive inertance control results are in between. It indicates that semiactive inertance control suspension can make fuller use of the 
TABLE 3: Natural frequencies and RMS values of BA.

\begin{tabular}{lcccc}
\hline & $f_{1}(\mathrm{~Hz})$ & Peak value $f_{1}\left(\mathrm{~m} \mathrm{~s}^{-2}\right)$ & $f_{2}(\mathrm{~Hz})$ & Peak value $f_{2}\left(\mathrm{~m} \mathrm{~s}^{-2}\right)$ \\
\hline Passive (unload) & 1.99 & 3.950 & 10.59 & 1.532 \\
Passive (full load) & 1.19 & 2.695 & 10.59 & 0.184 \\
Semiactive & 1.26 & 1.140 & 10 & 1.427 \\
\hline
\end{tabular}

TABLE 4: RMS values of time responses to a random excitation.

\begin{tabular}{lccc}
\hline & BA $\left(\mathrm{m} \mathrm{s}^{-2}\right)$ & SWS $(\mathrm{m})$ & DTL $(\mathrm{kN})$ \\
\hline Passive (unload) & 2.08 & 0.0086 & 2.17 \\
Passive (full load) & 1.02 & 0.0166 & 2.43 \\
Semiactive & 1.48 & 0.0109 & 1.99 \\
\hline
\end{tabular}

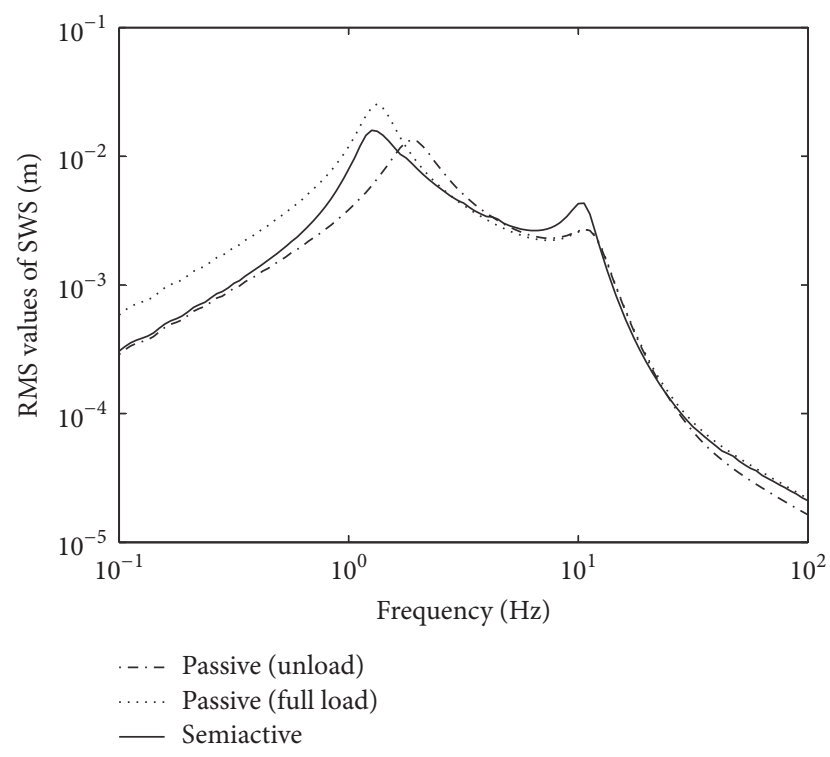

FIGURE 6: Frequency responses of suspension working space.

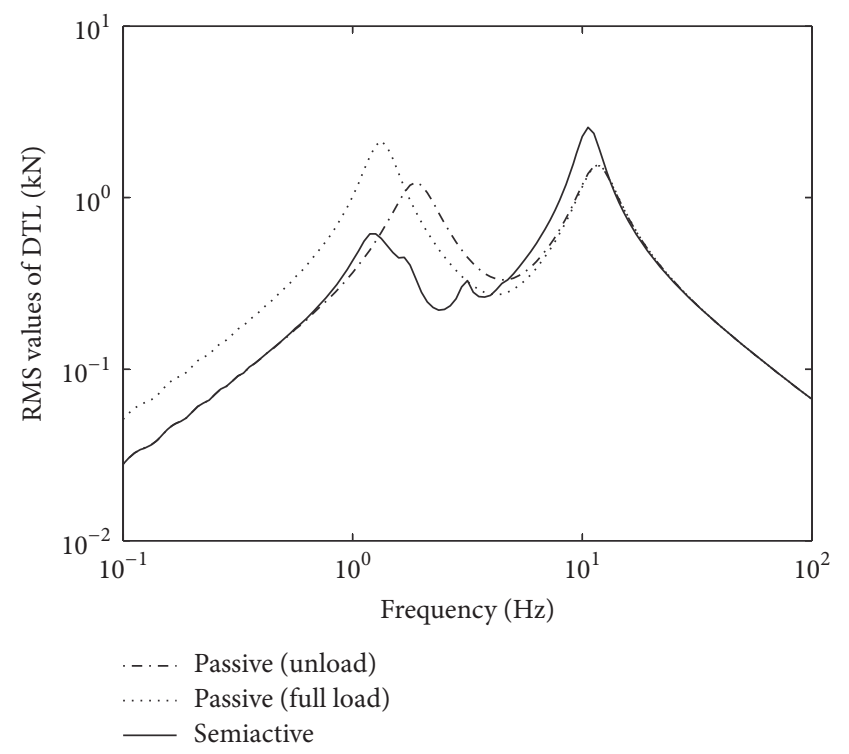

FIGURE 7: Frequency responses of dynamic tire load.

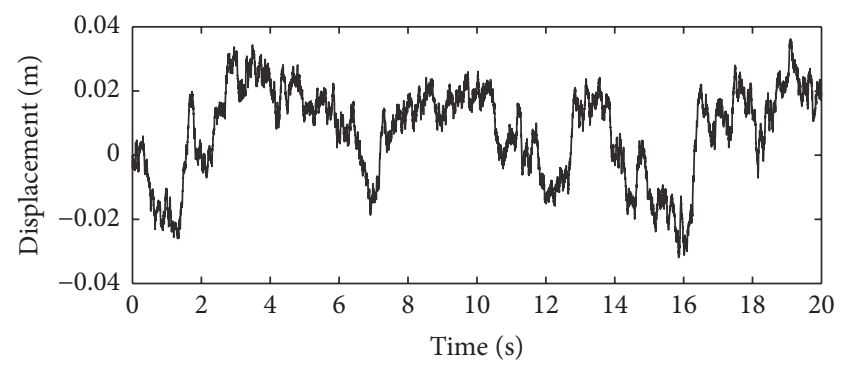

Figure 8: Road input.

suspension stroke compared with the passive suspension in unload condition.

Figure 7 shows the RMS values of the dynamic tire load (DTL) of the three suspensions in various frequencies. It can be seen that the RMS values of DTL of the semiactive inertance control suspension are dominant in the range of $1-3 \mathrm{~Hz}$, but slightly worse compared with the passive suspension in the range of $10-15 \mathrm{~Hz}$.

6.2. Time Responses to a Random Excitation. The response to a random excitation simulates a vehicle traveling on an actual road. A filtered white noise signal is taken as road input model [30]; that is,

$$
\dot{z}_{0}(t)=-2 \pi f_{0} z_{0}(t)+2 \pi \sqrt{G_{0}} v w(t),
$$

where $z_{0}(t)$ is road displacement in $\mathrm{m}, G_{0}$ is road roughness coefficient in $\mathrm{m}^{3}$ cycle ${ }^{-1}$, which is assumed to be $5 \times 10^{-6} \mathrm{~m}^{3}$ cycle ${ }^{-1}$ in this study, $v$ is vehicle forward speed in $\mathrm{m} \mathrm{s}^{-1}$, which is assumed to be $20 \mathrm{~m} \mathrm{~s}^{-1}, w(t)$ is zero-mean Gaussian white noise with intensity 1 , and $f_{0}$ is low cut-off frequency, which is assumed to be $0.0628 \mathrm{~Hz}$. The road displacement input is shown in Figure 8.

The results of time responses to a random excitation are shown in Figures 9-11, and the RMS values are listed in Table 4.

As can be seen in Figure 9, the amplitudes of BA values are less in the unload passive suspension and more in the fullload passive suspension, and semiactive inertance control 


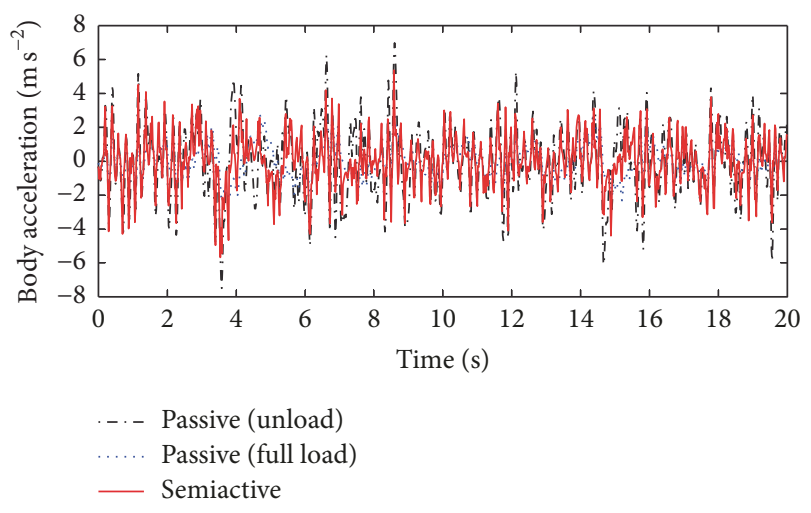

Figure 9: Body acceleration.

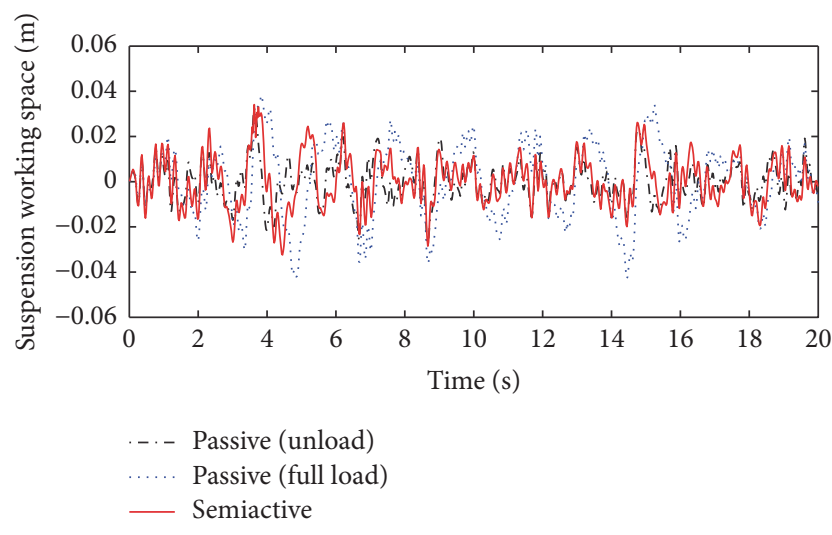

FIGURE 10: Suspension working space.

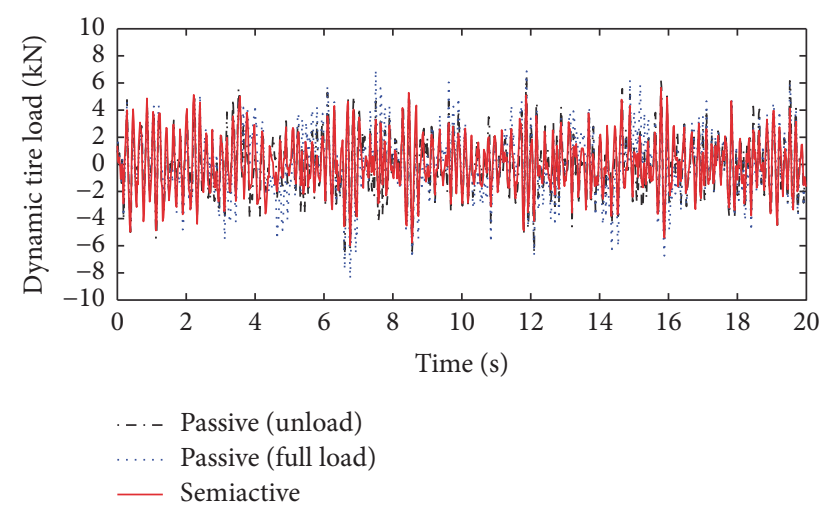

Figure 11: Dynamic tire load.

results are in between. According to Table 4, the RMS value of BA of semiactive inertance control suspension has $28.8 \%$ reduction compared with the passive suspension in unload condition. Although semiactive control suspension cannot obtain the ride comfort of the full-load passive suspension, it can be concluded that semiactive control can significantly obtain ride comfort improvement compared with the unload passive suspension, owing to that it can make fuller use of the suspension stroke. This implies the semiactive inertance control suspension can obtain desirable ride comfort in both unload and full-load condition. More importantly, there is no significant deterioration in suspension working space and dynamic tire load, as shown in Table 4 and Figures 10 and 11.

\section{Conclusions}

The performance of the semiactive suspension employing a modified skyhook-inertance control strategy was studied. This modified control strategy was proposed to adapt to the parasitic damping inherent in the hydraulic device of continuously adjustable inertance, so that the device can be controlled to approximate the virtual skyhook inerter which is not passively implemented in moving vehicles. In the modified control strategy, the resultant force including the inertial force and the parasitic damping force generated by the hydraulic device is set to equal the force generated by the virtual skyhook inerter, to virtually increase mass to the sprung mass. The semiactive suspension exhibits good performance of frequency responses to sinusoidal excitations owing to its lower sprung mass natural frequency. It has shown good reduction of vibration at sprung mass natural frequency without significant deterioration at higher frequencies. Also, the RMS values of time responses to a random excitation demonstrate the semiactive suspension achieves over $28 \%$ improvement on ride comfort, compared with the passive suspension in unload condition. This implies the semiactive suspension can obtain desirable ride comfort in both unload and full-load condition. Moreover, the simulation results of suspension working space and dynamic tire load show that the semiactive suspension is considered as a good compromise between ride comfort, suspension displacement, and road holding.

In this paper, the quarter vehicle model is used to evaluate the vertical vibration performance of the semiactive suspension system employing the modified skyhookinertance control strategy. Although the parasitic damping inherent in the hydraulic device have been considered, the model is not suitable for evaluation of the pitch and roll vibration performances of vehicles. In the further work, fullvehicle and more practical vehicle models will be taken into consideration, and experimental research will be carried out to further evaluate the overall performance of the proposed control strategy.

\section{Conflicts of Interest}

The authors declare that there are no conflicts of interest regarding the publication of this paper.

\section{Acknowledgments}

This work was supported by the National Natural Science Foundation of China (Grant no. 51405202); the Natural Science Foundation of Jiangsu Province of China (Grant no. BK20130521); the China Postdoctoral Science Foundation (Grant no. 2015M570408); the Six Talent Peaks Program of Jiangsu Province of China (Grant no. 2016-GDZB-097); and the Startup Foundation for Advanced Professional Talents of Jiangsu University (Grant no. 13JDG033). 


\section{References}

[1] P. Li, J. Lam, and K. C. Cheung, "Investigation on semiactive control of vehicle suspension using adaptive inerter," in Proceedings of the 21st International Congress on Sound and Vibration 2014, ICSV 2014, pp. 3367-3374, chn, July 2014.

[2] A. L. Do, O. Sename, L. Dugard, S. Savaresi, C. Spelta, and D. Delvecchio, "An extension of mixed sky-hook and ADD to magneto-rheological dampers," in Proceedings of the 4th IFAC Symposium on System, Structure and Control, SSSC 2010, pp. 2531, Italy, September 2010.

[3] F. Yu and Y. Lin, Automotive system dynamics, Mechanical Industry Press, Beijing, China, 1st edition, 2005.

[4] I. M. Ibrahim, D. A. Crolla, and D. C. Barton, "The impact of the dynamic tractor-semitrailer interaction on the ride behaviour of fully-laden and unladen trucks," SAE Technical Papers, 2004.

[5] R. K. Dixit and G. D. Buckner, "Sliding mode observation and control for semiactive vehicle suspensions," Vehicle System Dynamics, vol. 43, no. 2, pp. 83-105, 2005.

[6] J. Swevers, C. Lauwerys, B. Vandersmissen, M. Maes, K. Reybrouck, and P. Sas, "A model-free control structure for the online tuning of the semi-active suspension of a passenger car," Mechanical Systems and Signal Processing, vol. 21, no. 3, pp. 1422-1436, 2007.

[7] A. Giua, M. Melas, C. Seatzu, and A. G. Usai, "Design of a predictive semiactive suspension system," Vehicle System Dynamics, vol. 41, no. 4, pp. 277-300, 2004.

[8] F. D. Goncalves and M. Ahmadian, "A hybrid control policy for semi-active vehicle suspensions," Shock and Vibration, vol. 10, no. 1, pp. 59-69, 2003.

[9] T. R. M. Rao and G. V. Rao, "Analysis of passive and semi active controlled suspension systems for ride comfort in an omnibus passing over a speed bump," International Journal of Research and Reviews in Applied Sciences, vol. 5, no. 1, pp. 7-17, 2010.

[10] M. C. Smith, "Synthesis of mechanical networks: the inerter," Institute of Electrical and Electronics Engineers Transactions on Automatic Control, vol. 47, no. 10, pp. 1648-1662, 2002.

[11] C. Papageorgiou, N. E. Houghton, and M. C. Smith, "Experimental testing and analysis of inerter devices," Journal of Dynamic Systems, Measurement, and Control, vol. 131, no. 1, pp. 1-11, 2009.

[12] A. Z. Matamoros-Sanchez and R. M. Goodall, "Novel mechatronic solutions incorporating inerters for railway vehicle vertical secondary suspensions," Vehicle System Dynamics, vol. 53, no. 2, pp. 113-136, 2015.

[13] M. Z. Q. Chen, Y. Hu, L. Huang, and G. Chen, "Influence of inerter on natural frequencies of vibration systems," Journal of Sound and Vibration, vol. 333, no. 7, pp. 1874-1887, 2014.

[14] Y. L. Hu, M. Z. Q. Chen, and Z. Shu, "Passive vehicle suspensions employing inerters with multiple performance requirements," Journal of Sound and Vibration, vol. 333, no. 8, pp. 2212-2225, 2014.

[15] Y. L. Hu, M. Z. Q. Chen, Z. Shu, and L. X. Huang, "Analysis and optimisation for inerter-based isolators via fixed-point theory and algebraic solution," Journal of Sound and Vibration, vol. 346, no. 1, pp. 17-36, 2015.

[16] Y. Luo, H. Sun, X. Wang, L. Zuo, and N. Chen, "Wind Induced Vibration Control and Energy Harvesting of Electromagnetic Resonant Shunt Tuned Mass-Damper-Inerter for Building Structures," Shock and Vibration, vol. 2017, Article ID 4180134, 2017.
[17] M. Z. Chen, K. Wang, Y. Zou, and J. Lam, "Realization of a special class of admittances with one damper and one inerter for mechanical control," Institute of Electrical and Electronics Engineers Transactions on Automatic Control, vol. 58, no. 7, pp. 1841-1846, 2013.

[18] M. Z. Q. Chen, K. Wang, Y. Zou, and G. Chen, "Realization of Three-Port Spring Networks With Inerter for Effective Mechanical Control," IEEE Transactions on Automatic Control, vol. 60, no. 10, pp. 2722-2727, 2015.

[19] M. Z. Q. Chen, K. Wang, C. Li, and G. Chen, "Realization of Biquadratic Impedances as Five-Element Bridge Networks," IEEE Transactions on Circuits and Systems I: Regular Papers, vol. 64, no. 6, pp. 1599-1611, 2017.

[20] M. C. Smith and F. U.-C. Wang, "Performance benefits in passive vehicle suspensions employing inerters," Vehicle System Dynamics, vol. 42, no. 4, pp. 235-257, 2004.

[21] F. Scheibe and M. C. Smith, "Analytical solutions for optimal ride comfort and tyre grip for passive vehicle suspensions," Vehicle System Dynamics, vol. 47, no. 10, pp. 1229-1252, 2009.

[22] M. Z. Q. Chen, C. Papageorgiou, F. Scheibe, F. C. Wang, and M. Smith, "The missing mechanical circuit element," IEEE Circuits and Systems Magazine, vol. 9, no. 1, pp. 10-26, 2009.

[23] A. Kuznetsov, M. Mammadov, I. Sultan, and E. Hajilarov, "Optimization of improved suspension system with inerter device of the quarter-car model in vibration analysis," Archive of Applied Mechanics, vol. 81, no. 10, pp. 1427-1437, 2011.

[24] F. C. Wang, M. K. Liao, B. H. Liao, W. J. Su, and H. A. Chan, "The performance improvements of train suspension systems with mechanical networks employing inerters," Vehicle System Dynamics, vol. 47, no. 7, pp. 805-830, 2009.

[25] C. Papageorgiou and M. C. Smith, "Positive real synthesis using matrix inequalities for mechanical networks: Application to vehicle suspension," IEEE Transactions on Control Systems Technology, vol. 14, no. 3, pp. 423-435, 2006.

[26] M. Z. Chen, Y. Hu, C. Li, and G. Chen, "Semi-active suspension with semi-active inerter and semi-active damper," IFAC Proceedings Volumes, vol. 47, no. 3, pp. 11225-11230, 2014.

[27] Y. Hu, M. Z. Q. Chen, S. Xu, and Y. Liu, "Semiactive Inerter and Its Application in Adaptive Tuned Vibration Absorbers," IEEE Transactions on Control Systems Technology, vol. 25, no. 1, pp. 294-300, 2017.

[28] Y. Hu, M. Z. Q. Chen, and Y. Sun, "Comfort-oriented vehicle suspension design with skyhook inerter configuration," Journal of Sound and Vibration, vol. 405, pp. 34-47, 2017.

[29] S. J. Swift, M. C. Smith, A. R. Glover, C. Papageorgiou, B. Gartner, and N. E. Houghton, "Design and modelling of a fluid inerter," International Journal of Control, vol. 86, no. 11, pp. 2035-2051, 2013.

[30] F. Yu and D. A. Crolla, "An optimal self-tuning controller for an active suspension," Vehicle System Dynamics, vol. 29, no. 1, pp. 51-65, 1998. 


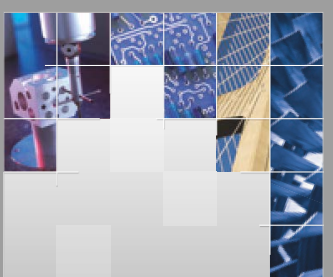

\section{Enfincering}
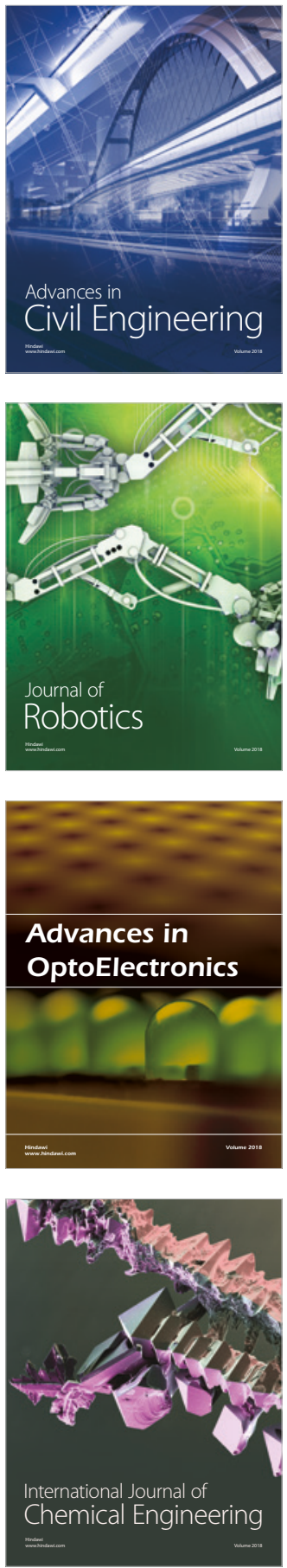

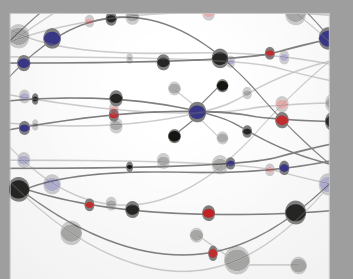

\section{Rotating \\ Machinery}

The Scientific World Journal

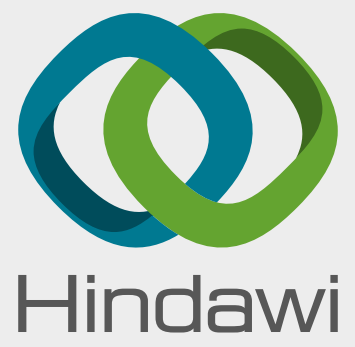

Submit your manuscripts at

www.hindawi.com
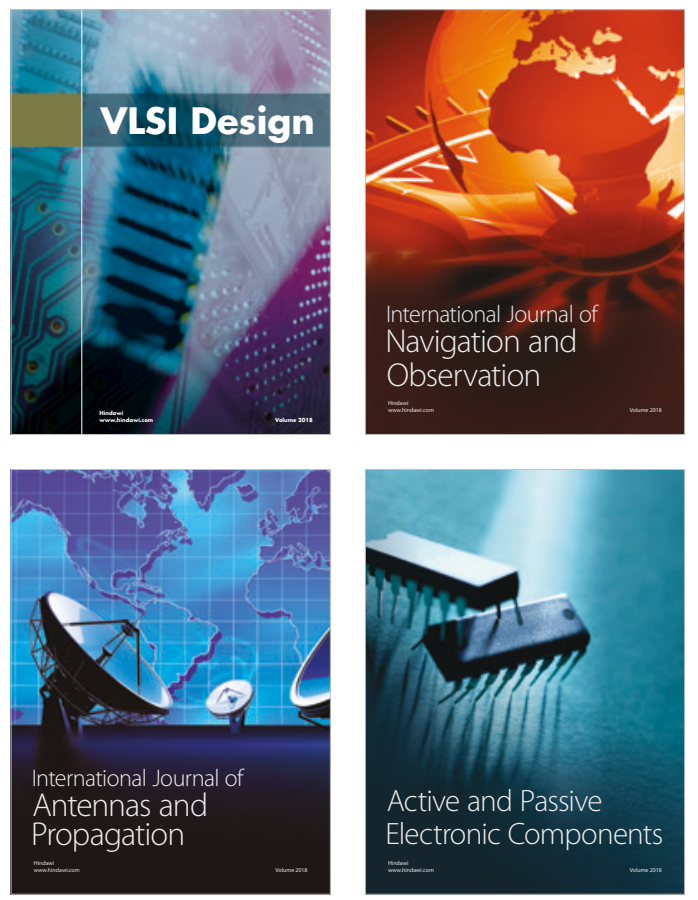
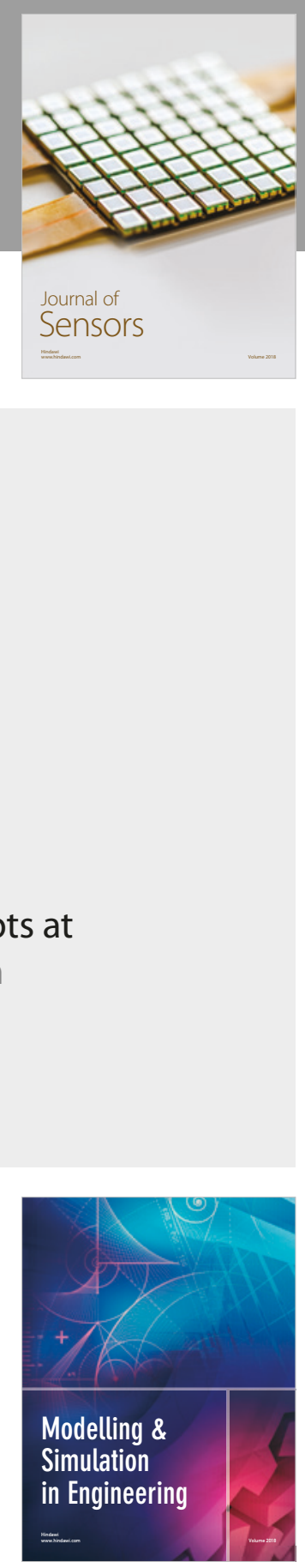

\section{Advances \\ Multimedia}
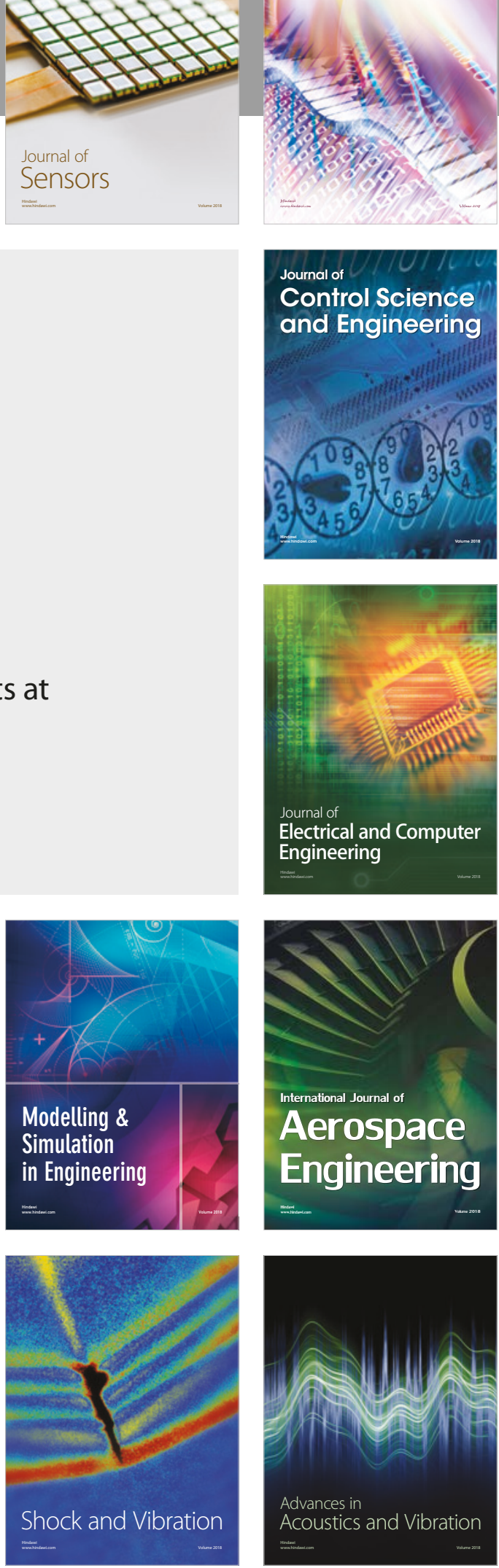